Available online on 15.1.2019 at http://ujpr.org
Universal Journal of Pharmaceutical Research
An International Peer Reviewed Journal
Open access to Pharmaceutical research

\title{
A COMPREHENSIVE REVIEW ON SUSTAINED RELEASE MATRIX TABLETS: A PROMISING DOSAGE FORM Prakhar Agarwal ${ }^{*}$ (D), Semimul Akhtar D \\ Department of Pharmacy, Shri Ram Murti Smarak College of Engineering \& Technology, Bareilly, UP, India.
}

\section{ABSTRACT}

Oral ingestion is most convenient and commonly employed route of drug delivery due to its ease of administration, least aseptic and flexibility in the design of dosage form. The objective of the study was to explore the necessity, advantages and various techniques of extended release matrix tablet to get a constant drug delivery rate and reproducible kinetics for advance delivery. Different types of extended release matrix tablet have been explained briefly along with the various formulation which mainly by wet granulation or direct compression method or by dispersion of solid particle within a porous matrix formed by using different polymers. Matrix controls the free rate of drug. Matrix tablets can be formulated by either direct compression or wet granulation method by using a variety of hydrophilic or hydrophobic polymers. The extended release matrix tablets can assure better patient compliance through reduction in total dose and dosage regimen, which can be great help to treat chronic diseases. This review highlights the types of matrices, mechanisms involved and evaluation studies.

Keywords: Controlled release, extended release, in-vitro dissolution, matrix tablet, polymers.

Article Info: Received 5 November 2018; Revised 9 December; Accepted 30 December, Available online 15 January 2019

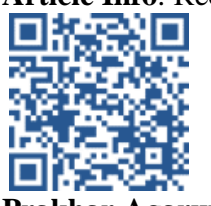

Cite this article-

Agarwal P, Semimul A. A comprehensive review on sustained release matrix tablets: a promising dosage form. Universal Journal of Pharmaceutical Research 2018; 3(6): 49-54.

DOI: https://doi.org/10.22270/ujpr.v3i6.222

Address for Correspondence:

Prakhar Agarwal, Department of Pharmacy, Shri Ram Murti Smarak College of Engineering \& Technology, Bareilly, UP, India. E-mail:prakhar055@gmail.com

\section{INTRODUCTION}

Drugs are administered with a main aim of treatment of the diseases. Drugs are never administered in their pure form but are converted in a suitable dosage forms so that its onset and intensity of action as well as total duration of action can be checked ${ }^{1}$. An ideal controlled drug delivery system is that which delivers the drug at a specific rate locally or systemically for a specified period of time with minimum fluctuation in plasma drug concentration, reduced toxicity and maximum efficiency. In present scenario conventional dosage forms of drugs are rapidly being replaced by the new and the novel drug delivery systems. Oral drug delivery is the most preferred and convenient route of drug administration due to high patient compliance, costeffectiveness, least sterility constraints, flexibility in the design of dosage form and ease of production ${ }^{1}$. Approximately $50 \%$ of the drug products available in the market are administered orally and historically, oral drug administration has been the predominant route for drug delivery as a result of more prominent strength, precision in dose, production ease, and formulation of tablets is favoured oral dosage form. Tablet accessibility in market ranges from generally straight forward immediate release formulation to complex sustained release or modified release dosage forms ${ }^{3}$.

Sustained release drug delivery system was meant to discharge the medication in a delayed rate to keep up plasma drug levels. The medications having shorter half life are appropriate for the sustained release drug delivery system. Matrix tablets is a promising approach for the establishment of extended-release drug therapy as tablets offer the lowest cost approach to sustained and controlled release solid dosage forms. Matrix tablets can be defined as the oral solid dosage forms in which the drug is homogeneously dispersed or dissolved within the hydrophilic or hydrophobic polymeric matrices. Hypothetically, sustained release dosage form should release the drug by a zero-order mechanism which maintains drug plasma level time similar to intravenous infusion ${ }^{4}$.

Matrix system is the release system which prolongs and controls the release of the drug, which is dissolved or dispersed. A matrix is defined as a well-mixed composite of one or more drugs with gelling agent i.e. hydrophilic polymers. Introduction of matrix tablet as sustained release has given a new breakthrough for novel drug delivery system in the field of Pharmaceutical technology. Under gastric $\mathrm{pH}$ 
conditions, matrix tablet slowly erodes. Two mechanisms are operative, either of which is zero-order erosion and decreasing surface area, and dissolution of coated particles. The result in the ability to control active pharmaceutical ingredient's blood level's in a narrow range, above the minimum effective level and below toxic level ${ }^{5}$.

The drug molecule appears better supported sustained drug release profile in matrix frameworks by distinctive systems. Matrix tablets may be formulated by wet granulation or direct compression methods by dispersing solid particles within a porous matrix formed of hydrophilic and hydrophobic polymers ${ }^{6-9}$.

Advantages of Sustained Release Matrix Tablets

\section{i) Patient compliance}

Lack of compliance is mainly seen with chronic disease which required long term treatment, as achievement of medication treatment relies upon the patient capacity to agree with the medication treatment. Patient compliance is affected by a many factors, like knowledge of ailment process, patient confidence in treatment, and understanding of patient related to a strict treatment plan. In addition to the difficulty of therapeutic regimens, the cost of therapy and local or systemic side effect of the dosage form. This issue can be set out to some degree by administering sustained release drug delivery system ${ }^{10-14}$.

\section{ii) Reduced 'see-saw' fluctuation}

Drug concentration in the systemic circulation and tissue compartments show 'see saw' pattern frequently when the drug administration in conventional dosage form. The sizes of these variances fundamentally rely upon drug kinetics such as the rate of absorption, distribution, elimination and dosing intervals ${ }^{15}$. The 'see-saw' pattern is more prominent just in case of drugs with biological half-life less than four hours, since recommended dosing intervals are rarely less than four hours. A well-designed sustained release drug delivery system can widely reduce the frequency of drug dosing and also maintain a steady drug concentration in blood circulation and target tissue cells ${ }^{16}$

\section{iii) Total dose reduction}

To treat an ailing condition less measure of aggregate drug is used in Sustained release drug delivery systems. By reducing the total amount of drug, decrease in systemic or local side effects are observed. This would also lead to greater economy ${ }^{17}$.

\section{iv). Improvement of deficiency in treatment}

Ideal treatment of a disease requires an effective transfer of active drugs to the tissues, organs that need treatment. Very often doses far in excess to those required in the cells have to be administered in order to achieve the necessary therapeutically effective concentration. This unfortunately may lead to undesirable, toxicological and immunological effects in non-target tissue. A sustained release dosage form leads to better management of the acute or chronic disease condition ${ }^{18}$.

\section{v). Economy}

The initial unit cost of sustained release products is typically more than that of conventional dosage form because of the special nature of these compounds but importantly average cost of treatment over an prolong period of time may be less ${ }^{19}$.

Disadvantages of sustained release matrix tablets

- Highly expensive.

- Often poor systemic availability.

- Need for additional patient education and counseling.

- $\quad$ Dose dumping ${ }^{20}$.

- Often poor in vivo-in vitro correlation ${ }^{21}$.

Characteristics of Drug Suitable for sustained Release Tablet

The ideal physicochemical and pharmacokinetic qualities of medications which can be defined as extended release tablet are as per the following:

1. Atomic size ought to be beneath of 1000 Dalton.

2. Aqueous solvency ought to be in excess of 0.1 $\mathrm{mg} / \mathrm{ml}$ for $\mathrm{pH} 1$ to $\mathrm{pH} 7.8$.

3. The partition coefficient ought to be high ${ }^{5}$

4. Absorption mechanism ought to be diffusion and the general absorbability from all GI fragments discharge ought not to be impacted by $\mathrm{pH}$ and catalysts.

5. Elimination half-life ought to be between 2 to $8 \mathrm{hrs}^{7}$

6. Drugs ought not to metabolize before absorption it cause less bioavailability.

7. Absolute bioavailability ought to be at least $75 \%$ or more.

8. Absorption rate constant $(\mathrm{Ka})$ ought to be higher than discharge rate. Apparent volume of distribution (Vd) ought to be substantial.

9. Total clearance ought not to rely upon dosage ${ }^{15}$.

10. Elimination rate constant are required for design and therapeutic concentration (Css) ought to be low and smaller $(\mathrm{Vd})^{3,4,5}$.

Polymers used in sustained release tablet

The polymers most widely used in preparing matrix system include both hydrophilic and hydrophobic polymers.

a) Hydrophilic Polymers

Hydroxyl propyl methyl cellulose (HPMC), hydroxyl propyl cellulose(HPC), hydroxyl ethyl cellulose (HEC), Xanthan gum, Sodium alginate, poly(ethylene oxide), and cross linked homopolymers and copolymers of acrylic acid an-24 $^{22}$

\section{b) Hydrophobic Polymers}

This usually includes waxes and water insoluble polymers in their formulation ${ }^{25}$.

\section{c) Natural polymers}

Xanthan Gum, Guar Gum, Sodium Alginate, Pectin, Chitosan $^{25}$.

d) Biodegradable polymers

Polylactic acid (PLA), Polyglycolic acid (PGA), Polycaprolactone (PCL), Polyanhydrides, Polyorthoesters $^{26}$.

e) Non-biodegradable polymers

Polyethylene vinyl acetate (PVA), Polydimethylsiloxane (PDS), Polyether urethane (PEU), Polyvinyl chloride (PVC), Cellulose acetate (CA), Ethyl cellulose (EC) ${ }^{27}$.

Methods of preparation

1. Direct Compression 
In this method, finely powdered materials are compressed directly without changing the physical and chemical properties of the drug ${ }^{28}$.

\section{Wet Granulation}

In this method weighed quantities of drug and polymer are mixed with sufficient volume of the granulating agent. After enough cohesiveness was obtained, the mass is sieved and dried at $40^{\circ} \mathrm{C}$ and kept in a dessicator. Lubricants and Glidants are added and the tablets are compressed using a tablet compression machine $^{29}$

\section{Melt Granulation}

In melt granulation, meltable substance act as liquid binding agent and hence does not require the use of organic solvents. This substance can be added in the molten form over the substrate, which is then heated above its melting point. Various lipophilic binders such as Glyceryl Palmitostearate are used in melt granulation technique ${ }^{16}$

\section{Classification of matrix tablets}

\section{A. On the Basis of Retardant Material Used}

\section{Hydrophobic Matrices (Plastic matrices)}

In the hydrophobic matrix tablets, the active drug is dispersed in a tablet within a porous skeletal structure by direct compression of the drug with plastic materials. Sustained release is produced due to the fact that the dissolving drug has diffused through a network of channels that exist between compacted polymer particles $^{21}$. Examples of materials that have been used as inert or hydrophobic matrices include polyethylene, polyvinyl chloride, ethyl cellulose and acrylate polymers and their copolymers. The rate controlling step in these formulations is liquid penetration into the matrix. The possible mechanism of release of drug in such type of tablets is diffusion. Such types of matrix tablets become inert in the presence of water and gastrointestinal fluid ${ }^{30}$.

\section{Lipid Matrices}

These matrices prepared by the lipid waxes and related materials. Drug release from such matrices occurs through both pore diffusion and erosion. Release characteristics are therefore more sensitive to digestive fluid composition than to totally insoluble polymer matrix. Carnauba wax in combination with stearyl alcohol or stearic acid has been utilized for retardant base for many sustained release formulation.

\section{Hydrophilic Matrices}

Hydrophilic polymer matrix systems are widely used in oral controlled drug delivery because of their flexibility to obtain a desirable drug release profile, cost effectiveness, and broad regulatory acceptance. Hydrophilic matrix may be formulated by a wet granulation of the drug and hydrophilic matrix materials or by direct compression of the blended mixture of active ingredient and certain hydrophilic carriers ${ }^{17}$.

The formulation of the drugs in gelatinous capsules or more frequently, in tablets, using hydrophilic polymers with high gelling capacities as base excipients is of particular interest in the field of controlled release. When immersed in fluid the drug release is controlled by a gel diffusion barrier that is formed and tablet erosion $^{31}$.

\section{Fat- wax matrix tablet}

The strategies include in addition of drug into fat wax. The drug can be incorporated into fat wax granulations by spray congealing in air, blend congealing in an aqueous media with or without the aid of surfactant and spray-drying techniques. Granules are showered which get hard in air, mixing in a aqueous fluid media with or without the surfactant and dried by spray drying strategy. A suspension of drug and melted fat wax are solidify by utilizing fluidized-bed and steam jacketed blender or granulating with a solution of waxy material. In this type of matrix tablet, drug is discharged by straining and hydrolysis mechanism.

\section{Mineral Matrices}

Mineral matrices can be set up by utilizing polymers which are acquired from different types of sea weads. Examples includes Alginic acid which is a hydrophilic sugar. The polymers obtained from different species of seaweeds are used to prepare mineral matrices. Alginic acid, a hydrophilic carbohydrate obtained from brown seaweeds (Phaephyceae) by the use of dilute alkali ${ }^{32}$.

\section{B. On the basis of porosity of matrix}

\section{Macro porous Systems}

In such systems the diffusion of drug occurs through pores of matrix, which are of size range 0.1 to $1 \mu \mathrm{m}$. This pore size is larger than diffusant molecule size ${ }^{9}$

\section{Micro porous System}

Diffusion in this type of system occurs essentially through pores. For micro porous systems, pore size ranges between $50-200 \mathrm{~A}^{\circ}$, which is slightly larger than diffusant molecules size

3. Non-porous System: Non-porous systems have no pores and the molecules diffuse through the network meshes. In this case, only the polymeric phase exists and no pore phase is present ${ }^{6-9}$.

\section{On the basis of the way of matrix preparations}

\section{Floating matrix system}

In this type of matrix system, the bulk density of the matrix is lower than the gastric fluid in the stomach. After creating buoyancy in the stomach, the release of drug molecules from the matrix can occur slowly, which prolongs gastric residence time and thereby increases the bioavailability of fast release drug molecules $^{18}$

\section{2. pH sensitive matrix system}

In this type of matrix system, an enteric coating of the matrix system can provide protection for the drug from the harsh acidic media of the stomach. Thus, low $\mathrm{pH}$ sensitive drug molecules can reach the small intestine and colon safely. This matrix system works by releasing the enteric coated drug at a specifically high $\mathrm{pH}$ value in the GIT, where drug absorption can occur in the right location. $\mathrm{PH}$ sensitive polymers such as HPMC- phthalate or cellulose acetate phthalate can be used in this type of matrix system ${ }^{26}$.

\section{Mucoadhesive matrix system}

Mucoadhesive matrix systems are designed to enable prolonged retention in the gastric region for several hours and hence significantly prolong the gastric residence time of drugs. Prolonged gastric retention improves bioavailability. In this type of matrix system, the release of the drug is controlled over a period of time $^{18}$. The targeted tissues can be gastrointestinal, 
buccal, ocular, nasal, respiratory, rectal, urethral and vaginal tissues. In addition, this type of matrix system can be applied to any mucosal tissue in the body. The used materials in this system are swellable hydrophilic polymers which can interact with the glycoproteins being available in the mucous layer of the gut $^{27}$.

\section{Factors affecting drug release from matrix tablets}

\section{A. Physicochemical factors}

Dose size

In general, a single dose of $0.5-1.0 \mathrm{~g}$ is considered maximal for a conventional dosage form. Drugs with a large dose size (> 500mg) are difficult to formulate into a matrix system because of the requirements of high amounts of the polymer as well as other matrix formers (excipients). Compounds that require large dosing size can sometimes be given in multiple amounts or formulated into liquid systems ${ }^{33}$.

\section{Drug solubility}

Polymer erosion is more predominates in the case of the matrix with insoluble drugs, while with soluble drugs a combination of diffusion and erosion determine the release of the drug. Diffusion of the drug depends upon the concentration gradient across the medium which is a function of solubility thus a drug with high solubility shows faster release while poorly water soluble drugs $(<0.01 \mathrm{mg} / \mathrm{ml})$ often result in the incomplete release because of their poor solubility and dissolution rate in the matrix ${ }^{12}$. Drugs that exhibit $\mathrm{pH}$-dependent solubility particularly in gastrointestinal $\mathrm{pH}$ range are poor candidate for matrix system $^{34}$

\section{Ionization, pka and aqueous solubility}

Most drugs are weak acids or bases. Since the unchanged form of a drug preferentially permeates across lipid membranes, it is important to note the relationship between the pka of the compound and the absorptive environment. Delivery systems that are dependent on diffusion or dissolution will likewise be dependent on the solubility of the drug in aqueous media. These dosage forms must function in an environment of changing $\mathrm{pH}$, the stomach being acidic and the small intestine more neutral, the effect of Phone the release process must be defined ${ }^{35}$.

\section{Partition Coefficient}

When a drug is administered to the GI tract, it must cross a variety of biological membranes to produce a therapeutic effect in another area of the body ${ }^{7}$ Compounds which are lipophilic in nature having high partition coefficient are poorly aqueous soluble and it retain in the lipophilic tissue for the longer time. In case of compounds with very low partition coefficient, it is very difficult for them to penetrate the membrane, resulting in poor bioavailability. It is common to consider that these membranes are lipidic; therefore the partition coefficient of oil-soluble drugs becomes important in determining the effectiveness of membrane barrier penetration ${ }^{36}$.

\section{B. Biological factors \\ Biological half-life}

Therapeutic compounds with short half-life are generally are excellent candidate for SR formulation, as this can reduce dosing frequency. The usual goal of an oral sustained release tablet is to maintain therapeutic blood levels over an extended period of time. To achieve this, drug must enter the circulation at approximately the same rate at which it is eliminated. In general, drugs with half-life shorter than $2 \mathrm{hr}$ are poor candidates for sustained release preparation. Compounds with long half-lives, more than $8 \mathrm{hr}$ are also generally not used in sustaining form, since their effect is already sustained ${ }^{37}$.

\section{Absorption}

Absorption of the drug should occur at a relatively uniform rate over the entire length of small intestine. If a drug is absorbed by active transport or transport is limited to a specific region of intestine, SR preparation may be disadvantageous to absorption. One method to provide sustaining mechanisms of delivery for compounds tries to maintain them within the stomach. This allows slow release of the drug, which then travels to the absorptive site. Since the purpose of forming a SR product is to place control on the delivery system, it is necessary that the rate of release is much slower than the rate of absorption ${ }^{27}$.

Evaluation parameters for extend release matrix tablet

\section{Thickness and Diameter}

Thickness and diameter of tablets are determined using Vernier Caliper.

\section{Hardness of the Tablet}

Tablet hardness has been characterized as, "the force required breaking a tablet in a diametric compression test". For every formulation, the hardness of three tablets is examined utilizing Monsanto hardness analyzer; end point is recognized by breaking the tablet $^{8-11}$

\section{Friability}

Twenty tablets are weighed and placed in friabilator. The chamber is rotated for 4 minutes at a speed of 25 rpm. the tablets are removed from the chamber and weighed again. Loss in weight indicates friability. The tablets to be considered of good quality if loss in weight is less than $0.8 \%^{19}$.

\section{Weight variation test}

This is an important process which comes under quality control test as per standard in one batch all tablet ought to be in uniform weight. Twenty tablets are weighed to determine the average weight and compared with single tablet weight. The percentage weight variation is computed according to Indian Pharmacopoeial particular ${ }^{26}$.

\section{Determination of drug content}

The drug content of is determined by dissolving in a suitable solvent like $\mathrm{pH} 7.4$ phosphate buffer solution and sample are analyzed with the visible spectrophotometer and standard calibration curve of the pure drug ${ }^{19-23}$.

\section{In-vitro dissolution testing}

In vitro dissolution testing is a vital instrument for assessment of the best formulation. The test is carried out to measure the amount of time required for certain percentage of drug to go into the solution under the specific test conditions. Rotating paddle type and rotating basket type apparatus can be used as per pharmacopoeial standards or as mentioned in 
monograph of particular drug Dissolution testing is likewise used to characterize the biopharmaceutical attributes and to distinguish conceivable hazard, for example, potential nourishment impacts on bioavailability or interaction with different drugs ${ }^{18}$.

\section{CONCLUSION}

The focus of this review article has been on the formulation of extended release matrix tablets, benefits and drawback, various types of polymers, technique of preparation and assessment parameters. As compared to conventional counterparts matrix tablets offer better patient compliance, maintains constant plasma drug concentration level, reduces chances of toxicity and once a day drug therapy reduces overall cost of treatment. Above discussion ends up on the conclusion that matrix tablets are helpful to overcome the patient incompliance and effectiveness of dosage form in evoking desired therapeutic response related problems linked with conventional dosage forms. So, this extend release formulation can be a suitable formulation which an antidiabetic drug which can be incorporated and better pharmacological action can be achieved. This article may be beneficial for many researcher interested to work on the matrix tablets.

\section{ACKNOWLEDGEMENTS}

Authors wish to thanks the authority of Shri Ram Murti Smarak College of Engineering and Technology (Department of Pharmacy), Bareilly, for providing library and other facilities to complete successfully this review study.

\section{AUTHOR'S CONTRIBUTION}

The manuscript was carried out, written, and approved in collaboration with all authors.

\section{CONFLICT OF INTEREST}

No conflict of interest associated with this work

\section{REFERENCES}

1. Rohini Diwedi et al. Preparation and in vitro Evaluation of sustained release tablet formulations of Metformin $\mathrm{Hcl}$. Asian J Pharm Clin Res 2012:5(1):45-48.

2. M. Vijaya Laxmi, Krishna V. J Formulation and Evaluation of Aceclofenac Matrix Tablets using Ethyl Cellulose and Cellulose Acetate Phthalate: J Global Trends Pharm Sci 2014:5(3):1804-1810

3. Brahmankar DM and Jaiswal SB. 1995, Biopharmaceutics and Pharmacokinetics; "A Treatise" Vallabh Prakashan; $1^{\text {st }}$ Ed.:347- 352

4. Dunn CJ, Peters D. Metformin: a review of its pharmacological properties and therapeutic use in noninsulin-dependent diabetes mellitus. Drugs 1995; 49:721749. PMID: 387488

5. Zalte HD, Saudagar R.B. Review on Sustained Release Matrix Tablet. Int J Pharmacy Biol Sci 2013:3(4):17-29.

6. Hoffman A. Pharmacodynamics aspects of sustained release preparations. Adv Drug Delivery Rev.1998:33:185-199. https://doi.org/10.1016/S0169-409X(98)00027-1

7. Munday DC, Cox PJ. Compressed xanthan and karaya gum matrices: Hydration, erosion and drug release mechanisms. Int J Pharm 2000:203:179-192. https://doi.org/10.1016/S0378-5173(00)00444-0

8. Bhargava A, Rathore RPS, Tanwar YS, Gupta S, Bhaduka G. Oral sustained release dosage form an opportunity to prolong the release of drug. Int $\mathbf{J}$ Adv Res Pharm Bio Sci 2013:3(1):7-14.

9. Ali Alyahawi, Abdulmajed Alsaifi. Quality control assessment of different brands of ciprofloxacin $500 \mathrm{mg}$ tablets in Yemen. Universal J Pharm Res 2018; 3(4): 31-36. https://doi.org/10.22270/ujpr.v3i4.180

10. Chauhan M J, Patel SA. Aconcise review on sustained drug delivery system and its opportunities. Am J Pharm Tech Res 2012:2(2):227-238

11. Abdulmajed Alsaifi, Ali Alyahawi. Quality assessment of different brands of paracetamol tablets in Yemeni market. Universal J Pharm Res 2018; 3(4): 42-47. https://doi.org/10.22270/ujpr.v3i4.182

12. Venkatraman S, Davar N, Chester A., An overview of controlled release systems. Donald L Wise, Marcel Dekker Inc 2000; 2 :431- 465

13. Sujja A J, Munday DL, Cox PJ, Khan K, Relationship between swelling, erosion and drug release in hydrophilic natural gum mini matrix formulations. Eur J Pharm Sci 1998; 6(3):207-217.https://doi.org/10.1016/S0928-0987(97)00072-9

14. Nweje-Anyalowu Paul C, Anyalogbu Ernest AA, White Alalibo Jim. Design and evaluation of chronotherapeutic pulsatile drug delivery system of Cilnidipine. Universal J Pharm Res 2017; 2(5): 18-22. https://doi.org/10.22270/ujpr.v2i5.R4

15. Boniferoni MC, Rossi S, Ferrari $\mathrm{F}$, Bartoni $\mathrm{M}$, et al., Viscoelastic properties of gels. Int J Pharm Sci,1995:117:4148. https://doi.org/10.1006/jcis.1998.5892

16. Shah Murad Mastoi, Azmat Ali, Hina Aslam, Khalid Niaz. Comparision of antidyslipiemic potential of 80 milligrams of Fenofibrated with 8 grams of Nigella sativa seeds daily. Universal J Pharm Res 2017; 2(6): 50-52. https://doi.org/10.22270/ujpr.v2i6.R9

17. Patel KK, Patel MS, Bhatt NM, Patel LD, Pathak NL, Patel KJ., An overview: extended release matrix technology. Int J Pharm Chem Sci, 2012:1(2):828. https://doi.org/10.20959/wjpps20186-11835

18. Pundir S, Badola A, Sharma, D. Sustained release matrix technology and recent advance in matrix drug delivery system. Int J Drug Res Tech 2013: 3(1):12-20.

19. Jaimini M, Kothari A. Sustained release matrix type drug delivery system: Rev J of Drug Delivery Ther 2012: 2(6):142-148. https://doi.org/10.5681/bi.2012.027

20. Lieberman H A, Lachman L, kanig J L. The theory and practice of industrial pharmacy. $3^{\text {rd }}$ Edition. Varghese publishing house; 2014

21. Igwe J Chibueze, Emenike IV, Oduola AR. Formulation and evaluation of Finasteride sustained-release matrix tablets using different rate controlling polymers. Universal J Pharm Res 2016; 1(2): 25-31. https://doi.org/10.22270/ujpr.v1i2.R3

22. Kumar S, Kant S, Prashar B. A review on sustained release drug delivery system. Int J Inst Pharm life Sci 2012 :2(3):356-376

23. Oyeniran Taiwo Opeyemi, Obanewa opeyemi Adegbenro. Development and characterization of direct compressed matrix mini tablets of naproxen sodium. Universal J Pharm Res 2018; 3(5): 7-11. https://doi.org/10.22270/ujpr.v3i5.205

24. Kumar N, Roy Mahasweta, Kumar B, Puri Pooja, Hasan M. Formulation and evaluation of sustained released metformin hcl tablet using natural polymers. Int J Pharmacy Pharm Res 2016:6(2):217-237. https://doi.org/10.4103/0250-474x.91579

25. Prajapati B, Patel R, Patel D, Shah P. Metformin hydrochloride sustained release tablet using different matrixing tablet, e-Journal of Science and Technology (eJST). 2013:4(8):61-72.

26. Singh S, Virmani T, Virmani R, Kumar P, Mahlawat G. Fast dissolving drug delivery systems: formulation, preparation techniques and evaluation. Universal J Pharm Res 2018; 3(4): 60-69. https://doi.org/10.22270/ujpr.v3i4.185

27. Singh A, Rajput DS, Gopalrao AA, Chauhan D, Mafidar R, Bhowmick M, Rathi J, Mathur R, Design and characterization of sustained release matrix tablets of 
metformin hydrochloride using combination of hydrophilic polymers. J Drug Deliv Therap 2018; 8(2):96-101. https://doi.org/10.4103/2229-516X.112242

28. Kanke PK, Sawant P, Jadhav A, Usman MRM. A review on disintegration control matrix tablets. J Drug Deliv Therap 2018; 8(5):19-22. https://doi.org/10.22270/jddt.v8i5.1852

29. Bookya P, Raparla R, Prasad Sriramula1, Harikishan, Tarrigopula Sunitha, Vanga Sridhar. Formulation and Evaluation of Metformin hydrochloride sustained-Release Oral Matrix Tablets. Asian J Pharm Clin Res 2018 :11(3):342-345. https://doi.org/10.4103/0250-474x.91579

30. Saddam C Shaikh, Dnyaneshwar Sanap, Dipak V Bhusari, Shirish Jain, Pooja P Kochar, Vikram N Sanchati. Formulation and evaluation of Ibuprofen gastro-retentive floating tablets. Universal J Pharm Res 2018; 3(4): 20-25. https://doi.org/10.22270/ujpr.v3i4.178

31. Mohanty S, Pal Abhisek, Chandra Si Sudam. Evaluation of Sustained Release Tablet of Metformin in Alloxan Induced Diabetic Rat. Int J Pharmaceutical Sciences Review and Research 2017;47 :133-140.
32. Satyanarayana T, Rajitha V, Kumar SP., Ravinder K., Shaji G. and Saranya P. Formulation and evaluation of Metformin $\mathrm{HCl}$ extended release tablets, Pelagia Research Library 2012; 3(1):58-63. https://doi.org/10.4103/0250-474x.91579

33. Patil DM, Pawar PA, Pagar RY, Ghule RS, Bairagi VA, Formulation and development of sustained release matrix tablets of lornoxicam. J Drug Delivery Therap 2018; 8(2):102-106

34. Verma BK, Pandey S, Arya P. Tablet granulation: current scenario and recent advances. Universal J Pharm Res 2017; 2(5): 34-39. https://doi.org/10.22270/ujpr.v2i5.RW1

35. Chauhan V, Kumar K, Teotia D. Fast dissolving tablets: a promising approach for drug delivery. Universal J Pharml Res 2017; 2(4): 58-64. https://doi.org/10.22270/ujpr.v2i4.RW4

36. Cox PJ, Khan KA., Munday DL, Development and evaluation of a multiple-unit oral sustained release dosage form for $\mathrm{S}(+)$-ibuprofen: preparation and release kinetics. Int J Pharm 1999; 193: 73 - 84

https://doi.org/10.1016/s0378-5173(99)00320-8

37. Misal R, Atish W, Aqueel S. Matrix tablets: A promising Technique for controlled drug delivery. Indo Am J Pharm Res 2013;3(5):3791-805.PMID: 21589795 